\title{
Distinct modes of cyclin E/cdc2c kinase regulation and S-phase control in mitotic and endoreduplication cycles of Drosophila embryogenesis
}

\author{
Karsten Sauer, ${ }^{1,3}$ Jürgen A. Knoblich, ${ }^{1,3,4}$ Helena Richardson, ${ }^{2}$ and Christian F. Lehner ${ }^{1,5}$

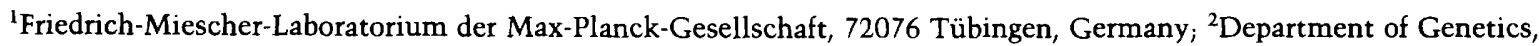 \\ University of Adelaide, South Australia 5005, Australia
}

\begin{abstract}
Drosophila cyclin $E$ (DmcycE) is required in embryos for $S$ phase of mitotic and endoreduplication cycles. Here, we describe regulatory differences characteristic for these two cell cycle types. While $D m c y c E$ transcript levels decline in DmcycE mutant cells programmed for mitotic proliferation, they are maintained and no longer restricted to transient pulses in $D m c y c E$ mutant cells programmed for endoreduplication. Moreover, $D m c y c E$ expression in endoreduplicating cells is down-regulated by ectopic expression of a heat-inducible cyclin $E$ transgene. DmcycE expression in endoreduplicating tissues, therefore, is restricted by a negative feedback to the transient pulse triggering entry into S-phase. Conversely, during mitotic cycles, where $S$ phase entry is not only dependent on cyclin $E$ but also on progression through $M$ phase, cyclin $E$ and associated Dmcdc2c kinase activity are present throughout the cell cycle. Reinitiation of DNA replication during the $\mathbf{G}_{2}$ phase of the mitotic cell cycle, therefore, is prevented by cyclin E/Dmcdc2c kinase-independent regulation. Observations in cyclin A mutants implicate $G_{2}$ cyclins in this regulation. Our results suggest molecular explanations for the different rules governing $S$ phase during mitotic and endoreduplication cycles.
\end{abstract}

[Key Words: Cyclin A; cyclin E; Dmcdc2c kinase; S phase; endoreduplication; Drosophila]

Received December 1, 1994; revised version accepted April 11, 1995.

The essential steps of the mitotic cell cycle, $S$ and $M$ phase, have to be strictly alternating to preserve genome ploidy. Recent progress in understanding the regulation of entry into $S$ and $M$ phase provides a basis for the analysis of the molecular mechanisms that maintain the correct temporal order of these essential events. Entry into both $S$ and $M$ phase is controlled by cyclin-dependent kinases. Specialized cyclins and cdc2-like kinases control either the $G_{1} / S$ or the $G_{2} / M$ transition in higher eukaryotes (Fang and Newport 1991; Hamaguchi et al. 1992; Baldin et al. 1993; Knoblich and Lehner 1993; Quelle et al. 1993; Stern et al. 1993; van den Heuwel et al. 1993; Knoblich et al. 1994; for review, see Sherr 1993; Solomon 1993). The $G_{2} / M$ transition is controlled by the cdc2 kinase in association with $G_{2}$ cyclins /cyclins $A$ and B). In contrast, progression through the $G_{1}$ phase and entry into $S$ phase is controlled by the cyclin-dependent kinase $4 / 6$ (cdk4/6) and cdk2 in conjunction with $G_{1}$ cyclins (cyclins D and E).

Transcriptional control of cyclin expression in yeast

\footnotetext{
${ }^{3}$ These authors contributed equally to this work.

${ }^{4}$ Present address: Howard Hughes Medical Institute, University of California, San Francisco, California 94143-0724 USA.

${ }^{5}$ Corresponding author.
}

and vertebrate tissue culture cells results in a periodic and ordered accumulation of $G_{1}$ and $G_{2}$ cyclins and therefore, contributes to the ordered progression through the cell cycle. In budding yeast, this transcriptional control involves positive and negative feedback loops. The $G_{1}$ cyclins $C \ln 1$ and $C \ln 2$, as well as the $G_{2}$ cyclin Clb2, have been shown to stimulate the transcription of their own genes via positive feedback loops (Cross and Tinkelenberg 1991; Dirick and Nasmyth 1991; Amon et al. 1993). Importantly, the $G_{2}$ cyclin Clb2 is also capable of shutting off the transcription of the $G_{1}$ cyclins $C \ln 1$ and Cln2 (Amon et al. 1993).

A number of observations indicate that post-transcriptional mechanisms are also involved in ordering cell cycle phases. Replacing the periodic transcription of either $\mathrm{G}_{1}$ or $\mathrm{G}_{2}$ cyclins by continuous transcription throughout the cell cycle is not incompatible with an ordered cell cycle progression in budding yeast (see, e.g., Ghiara et al. 1991; Amon et al. 1994). Moreover, early embryonic cycles in many species, including Xenopus and Drosophila, rely exclusively on maternal stores deposited in the egg during oogenesis and proceed normally in the complete absence of transcription. A post-transcriptional mechanism, which is of paramount importance for the order of cell cycle phases, is the control of $G_{2}$ cyclin stability. 
The abrupt degradation of these proteins during mitosis results in the inactivation of the associated cdc2 kinase and allows exit from mitosis (Evans et al. 1983; Glotzer et al. 1991; Holloway et al. 1993; Surana et al. 1993). Recent observations in Drosophila and budding yeast indicate that the reaccumulation of $G_{2}$ cyclins after mitosis is dependent on the presence of $G_{1}$ cyclins (Amon et al. 1994; Knoblich et al. 1994). The $G_{2}$ cyclin degradation system, which is activated during mitosis, appears to remain active in the following interphase until it is inactivated by $G_{1}$ cyclins. Thus, $G_{2}$ cyclin accumulation after mitosis cannot occur prior to $G_{1}$ cyclin accumulation. This control, therefore, presumably prevents entry into a second mitosis before entry into $\mathrm{S}$ phase has occurred, and additional checkpoint mechanisms assure that entry into mitosis occurs only after completion of $S$ phase (Weinert and Hartwell 1988; Enoch et al. 1992; Kelly et al. 1993; Saka and Yanagida 1993; Weinert et al. 1994).

Here, we address the controls that prevent entry into a second $\mathrm{S}$ phase before mitosis has occurred. An attractive model for this regulation invokes a licensing factor that has been postulated based on elegant experiments with Xenopus egg extracts but not yet identified molecularily (Blow and Laskey 1988; Blow 1993; Coverley et al. 1993|. According to this model, entry into $S$ phase is dependent on the presence of licensing factor in the nucleus. Licensing factor is postulated to accumulate in the cytoplasm during interphase. Access to the nucleus is only possible after nuclear envelope breakdown during mitosis. Moreover, nuclear licensing factor is thought to be consumed during S phase.

Drosophila allows a comparison of S-phase regulation during mitotic cell cycles and endoreduplication cycles. Most postmitotic cells in Drosophila development eventually enter endoreduplication cycles where they progress through several rounds of $S$ phase without intervening mitoses (Smith and Orr-Weaver 1991). The dependency of $S$ phase on progression through $M$ phase must be absent or bypassed in these endoreduplication cycles.

We have demonstrated recently that Drosophila cyclin $\mathrm{E}(D m c y c E)$ is required for entry into $S$ phase during mitotic and endoreduplication cycles (Knoblich et al. 1994). Moreover, ectopic expression of cyclin E after the final mitotic division is sufficient to force the postmitotic cells into S phase, and the normal pattern of DmcycE expression determines the spatial and temporal program of endoreduplication during embryogenesis (Knoblich et al. 1994). We show here that the brief pulses of $D m c y c E$ expression that anticipate endoreduplication rely on a negative feedback loop whereby cyclin $\mathrm{E}$ down-regulates its own expression. Interestingly, this feedback inhibition is not observed in mitotically proliferating cells of the embryo. During the embryonic division cycles, cyclin $\mathrm{E}$ and the associated Dmcdc2c kinase are predominantly nuclear throughout interphase, and cyclin E-associated kinase activity is not inactivated during the $G_{2}$ phase. The mechanisms that prevent inappropriate endoreduplication during the $G_{2}$ phase of the mitotic cycle, therefore, are not dependent on the inactivation of cyclin
E-associated kinase activity. Our observations in cyclin A mutant embryos, however, suggest that $\mathrm{G}_{2}$ cyclins are required for preventing inappropriate endoreduplication during the $G_{2}$ phase of the mitotic cycle.

\section{Results}

The control of cyclin E transcription in endoreduplicating and mitotically proliferating tissues is distinct

To determine whether cyclin $\mathrm{E}$ can regulate its own expression, we expressed cyclin $E$ from a heat-inducible transgene $(H s-c y c l i n E)$ and analyzed the effect on the expression of the endogenous cyclin E gene $(D m c y c E)$. The results of these experiments are illustrated in Figure 1. A 30-min heat pulse resulted in abundant expression of $H s-c y c l i n E$ as visualized by in situ hybridization with an antisense RNA probe derived from the cyclin box region of $D m c y c E$. As expected, transcripts were detected in all cells of the $H s-c y c l i n E$ embryos immediately after a heat pulse at stage 13 , and these transcripts were found to disappear slowly within $60 \mathrm{~min}$ of recovery at $25^{\circ} \mathrm{C}$ (Fig. 1G-I). Expression from the endogenous cyclin E gene was analyzed with a probe derived from the $3^{\prime}$-untranslated region of $D m c y c E$ that is not included in the $H s-c y c l i n E$ transgene. The transcripts from the endogenous $D m c y c E$ gene were not distributed throughout the embryo. DmcycE transcripts were found predominantly in cells of the developing central nervous system [CNS (Fig. 1D-F)], where cells are known to proliferate mitotically at this stage. Only very weak signals were present in internal tissues that are known to progress through endoreduplication cycles at this stage (Fig. $1 \mathrm{~F}$, arrowheads). Interestingly, signals were much stronger in these internal tissues when the same probe was used for in situ hybridization with control embryos that did not carry the $H s$-cyclin $E$ transgene but had also been exposed to a 30-min heat pulse (Fig. 1C, arrowheads). The same transcript distribution and levels as in the heatshocked controls that did not carry the $H s-c y c l i n E$ transgene were also obtained with $H s-c y c l i n E$ or wildtype embryos that had not been exposed to a heat pulse (Knoblich et al. 1994; data not shown). These observations indicate that ectopic $H s-c y c l i n E$ expression inhibits the endogenous $D m c y c E$ transcription only in endoreduplicating tissues and not in mitotically proliferating cells of the CNS. The inhibition was maximally apparent after $60 \mathrm{~min}$ of recovery (Fig. 1, cf. C and F).

The opposite effect, induction by ectopic $H s$-cyclin $E$ expression, has been reported in the case of S-phase-specific genes like Ribonucleotide reductase (DmRNR1, DmRNR2), DNA polymerase $\alpha$, and PCNA (Duronio and O'Farrell 1994). As a control, therefore, we hybridized aliquots of embryos with a $D m R N R 2$ probe. As described previously (Duronio and O'Farrell 1994), DmRNR2 transcripts were found to be induced by ectopic $H s-c y c l i n E$ expression with a maximum after $60 \mathrm{~min}$ of recovery (Fig. l, cf. L and O).

In a further experiment we investigated whether 


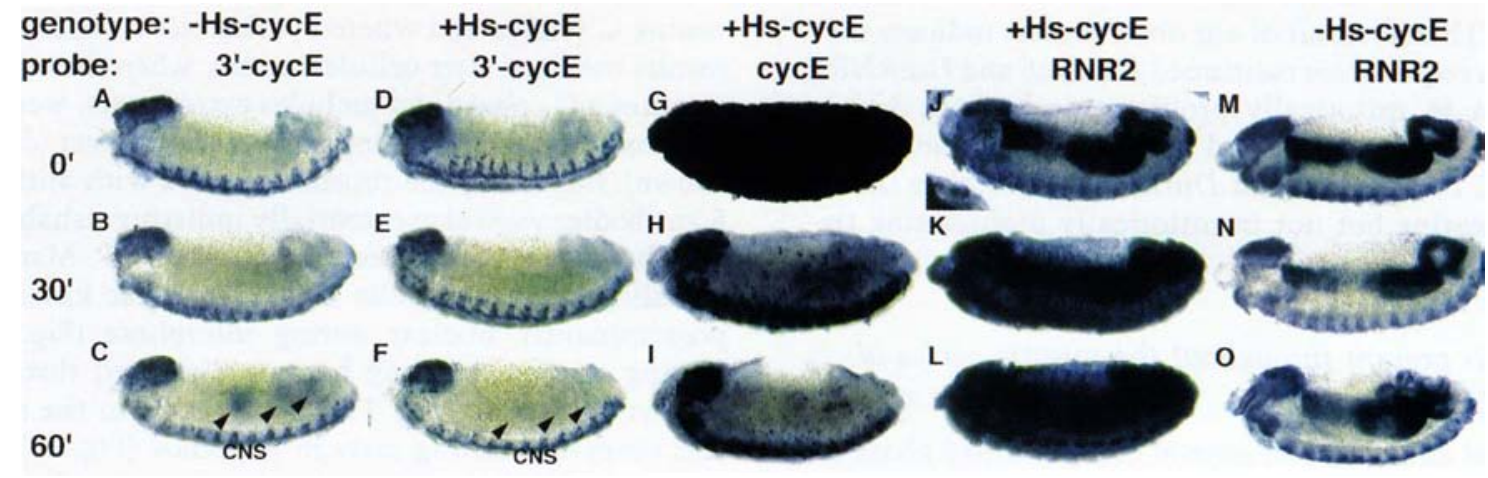

Figure 1. The effect of ectopic $H s-c y c l i n E$ expression on the expression of the endogenous $D m c y c E$ gene. Embryos either without the $H s-c y c l i n E$ transgene $(-\mathrm{Hs}-\mathrm{CycE}: A-C, M-O)$ or with the $H s-c y c l i n E$ transgene $(+\mathrm{Hs}-\mathrm{cycE}: D-L)$ were incubated at $37^{\circ} \mathrm{C}$ for $30 \mathrm{~min}$ and fixed either immediately $(0 \mathrm{~min})$ after the heat shock $\left(0^{\prime}: A, D, G, J, M\right)$, or returned to $25^{\circ} \mathrm{C}$ for either $30 \mathrm{~min}\left(30^{\prime}: B, E, H, K, N\right)$ or $60 \mathrm{~min}\left(60^{\prime}: C, F, I, L, O\right)$ before fixation and in situ hybridization. Transcripts derived from the endogenous $D m c y c E$ gene were detected with a probe hybridizing to $3^{\prime}$-untranslated sequences $\left(3^{\prime}\right.$-cycE: $\left.A-F\right)$. Transcripts derived from the $H s-c y c l i n E$ transgene and the $D m c y c E$ gene were detected with a probe hybridizing to coding sequences (cycE: $G-I$ ). Transcripts derived from the Drosophila RNR2 gene were detected with a DmRNR2 probe (RNR2: $I-O)$. Arrowheads in $C$ and $F$ indicate $D m c y c E$ transcripts in endoreduplicating tissues (midgut, Malpighian tubules) that are down-regulated by $H s-c y c l i n E$ expression (cf. $C$ and $F$ ). In contrast, $D m R N R 2$ transcripts are up-regulated after $H s-c y c l i n E$ expression (cf. $L$ and $O$ ).

$D m c y c E$ transcription is dependent on cyclin E activity. The $D m c y c E^{A R 95}$ mutation introduces a premature termination codon into the cyclin box region destroying all function according to phenotypic analyses (Knoblich et al. 1994). A comparison of homozygous mutant and control embryos revealed interesting differences after in situ hybridization with a DmcycE probe. Analogous differences were also observed after in situ hybridization with a DmRNR2 probe. Compared with control embryos (Fig. 2A-D), homozygous cyclin E mutant embryos (Fig. 2E$\mathrm{H})$ had weaker signals in the region of the CNS and stronger signals in internal tissues (see arrowheads in Fig. 2). A developmental analysis indicated that these differences became apparent at stage 13. This is clearly after stage 12 where the arrest of DNA replication becomes apparent in homozygous DmcycE mutants (Knoblich et al. 1994). Initially, DmcycE mutants develop normally presumably until the exhaustion of the maternal cyclin E contribution (Knoblich et al. 1994). The in situ hybridization experiments in $D m c y c E$ mutants indicate that the late zygotic expression of $D m c y c E$ and $D m R N R 2$ is dependent on cyclin E function but only in regions that continue to proliferate mitotically in control embryos. In contrast, DmcycE and DmRNR2 expression continued in the absence of cyclin $E$ function in internal tissues, which in control embryos progress through endoreduplication cycles. The onset of $D m c y c E$ and DmRNR2 trarıscription in internal tissues occurred in the normal temporal and tissue-specific pattern that anticipates endoreduplication $S$ phases in wild-type embryos (Duronio and O'Farrell 1994; Knoblich et al. 1994). However, whereas DmcycE and DmRNR2 are expressed only during a brief pulse in wild-type embryos, expression was maintained in homozygous $D m c y c E$ mutant
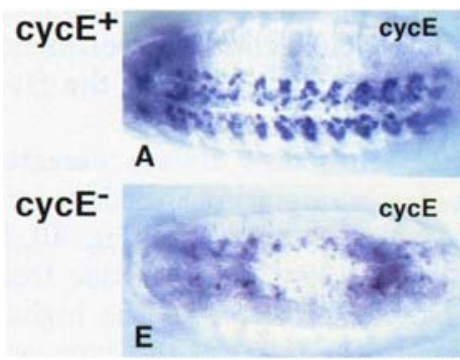
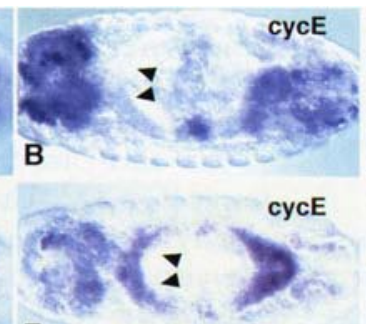

$\mathbf{F}$

cycE

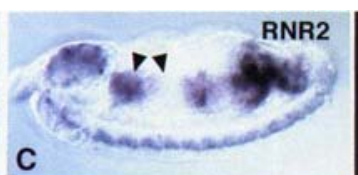

C
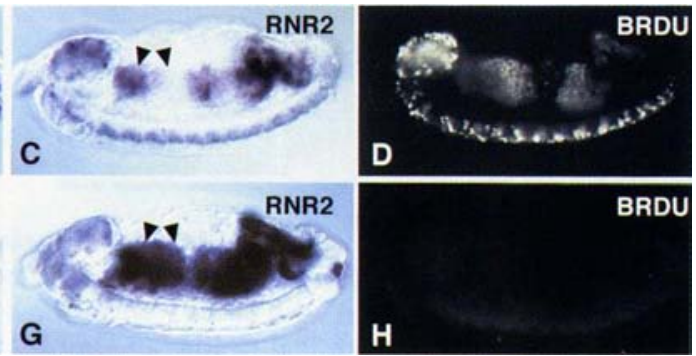

Figure 2. $D m c y c E$ and $D m R N R 2$ transcription in $D m c y c E$ mutant embryos. Homozygous $D m c y c E^{A R 95}(E-H)$ or sibling embryos $(A-D)$ were fixed and used for in situ hybridization with either a $D m c y c E$ probe (cycE: $A, B, E, F)$ or a $D m R N R 2$ probe (RNR2: $C, G)$. The comparison of the ventral views shown in $A$ and $E$ reveals reduced $D m c y c E$ transcript levels in the CNS of $D m c y c E$ mutants. The comparison of the dorsal views shown in $B$ and $F$ reveals increased $D$ mcycE transcript levels in the anterior midgut (arrowheads) of $D m c y c E$ mutants. Comparison of the lateral views shown in $C$ and $G$ reveals the same behavior in the case of $D m R N R 2$ transcripts. BrdU pulse-labeling before fixation and in situ hybridization allowed the identification of homozygous $D m c y c E^{A R 95}$ embryos among the progeny of the heterozygous parents $\left(D m c y c E^{A R 95} / C y O\right)$. Homozygous $D m c y c E^{A R 95}$ embryos do not incorporate BrdU (Knoblich et al. 1994). BrdU double-labeling of the embryos shown in $C$ and $G$ is shown in $D$ and $H$, respectively. 
embryos. Therefore, all of our observations indicate that cyclin E is required for continued DmcycE and DmRNR2 expression in mitotically proliferating but not in endoreduplicating tissues, and vice versa, for the downregulation of DmcycE and DmRNR2 expression in endoreduplicating but not in mitotically proliferating tissues.

\section{Cyclin $E$ is present throughout the mitotic cycles of embryogenesis}

The spatial and temporal control of entry into $S$ phase by pulses of cyclin $\mathrm{E}$ transcription, which regulates endoreduplication during the second half of embryogenesis (Knoblich et al. 1994), is not observed during the preceding mitotic proliferation (Richardson et al. 1993). Immunofluorescence experiments with antibodies against cyclin $\mathrm{E}$ and Dmcdc2c kinase revealed that these proteins, which are known to be associated in vivo (Knoblich et al. 1994), are continuously present throughout the early embryonic cycles. Figure 3 illustrates the results obtained with anti-Dmcdc2c antibodies during the early syncytial cycles, where $S$ and $M$ phases alternate without inter-

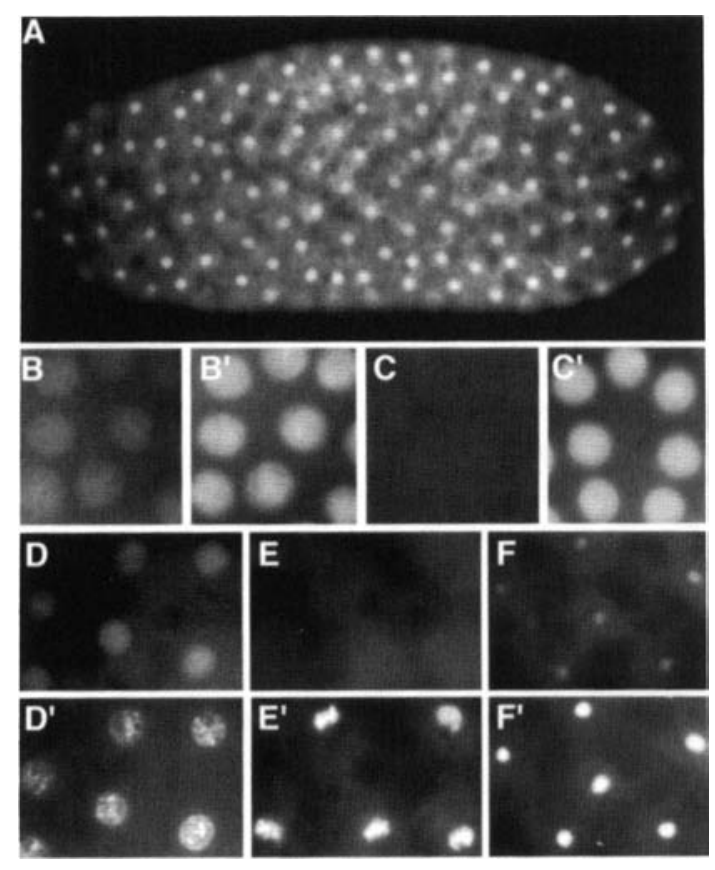

Figure 3. Immunofluorescent localization of Dmcde2c kinase in interphase and mitosis. Early embryos during the syncytial stages were fixed and double-labeled with affinity-purified rabbit antibodies against a carboxy-terminal peptide of Dmcdc2c kinase $(A-C)$ or a monoclonal antibody specific for Dmcdc2c kinase $(D-F)$ and the DNA stain Hoechst $33258\left(B^{\prime}-F^{\prime}\right)$. To demonstrate the specificity of the carboxy-terminal antibodies, we added either a control peptide $(B)$ or the peptide used for immunization $(C)$ as a competitor during the incubation with the primary antibody. During mitosis, Dmcdc2c kinase is still predominantly nuclear early in prophase $\langle D|$, distributed in the cytoplasm during metaphase $(E)$, and again predominantly nuclear in telophase $(F)$. vening $G$ phases and where cytokinesis is omitted. The results obtained after cellularization, when the cell cycle acquires $\mathrm{a}_{2}$ phase and includes cytokinesis, were identical except that signal intensities were lower (data not shown). Moreover, the results obtained with anti-cyclin $\mathrm{E}$ antibodies were also essentially indistinguishable /data not shown; H. Richardson, L.V. O'Keefe, T. Marty, and R. Saint, in prep.). Cyclin E and Dmcdc2c kinase were predominantly nuclear during interphase (Fig. 3A,B). During mitosis, labeling became dispersed throughout the cytoplasm (Fig. 3E). Reaccumulation in the nucleus was observed starting early in telophase (Fig. 3F).

Immunoblotting experiments confirmed and extended these observations. We synchronized cell cycle progression by using string mutant embryos carrying a heatinducible string transgene ( $\mathrm{Hs}-$ string). The String/Cdc25 phosphatase is required for the activation of the $\mathrm{G}_{2}$ cyclin/Dmcdc2 kinase activity and, hence, for entry into mitosis (Edgar and O'Farrell 1989, 1990; Edgar et al. 1994). Cells in string mutant embryos arrest in the $G_{2}$ phase after cellularization. Hs-string expression forces these cells synchronously into mitosis and into $S$ phase of the following cell cycle (Edgar and O'Farrell 1990). Embryos in G2, early $M$ (pro- and metaphase), and at the beginning of the following $\mathrm{S}$ phase were selected under the microscope and analyzed by immunoblotting.

The results confirmed that cyclin $\mathrm{E}$ is present during the $G_{2}$ phase and is not degraded during mitosis, in contrast to cyclins A and B (Fig. 4A). At least two types of $D m c y c E$ transcripts are present in embryos: type I transcripts of zygotic origin, and type II transcripts of maternal origin (Richardson et al. 1993). The putative protein products of type I and II transcripts that differ in the amino-terminal regions (Richardson et al. 1993) were both detected by anti-cyclin $\mathrm{E}$ antibodies (Figs. 4A and 5D). Cyclin E forms with lower electrophoretic mobility (possibly reflecting phosphorylation) were found to be maximal during mitosis. The cyclin $\mathrm{E}$ form with the highest mobility was most abundant in the $G_{2}$ phase and almost absent during $M$ and early $S$ phase (Fig. 4A). The disappearance of this high mobility form results from the heat pulse applied during our experiments and does not correlate with cell cycle progression, as this form also disappeared after heat shock in control experiments with homozygous string embryos not carrying the Hs-string transgene (data not shown).

The anti-Dmcdc2c antibodies always detected two forms (Fig. 4A). The faster migrating Dmcdc2c form was clearly enriched in cyclin E complexes (Fig. 4B, lane 1; see also Knoblich et al. 1994). Phosphatase treatment shifted the lower Dmcdc2c band into the higher band (Fig. 4B). An increase in the faster at the expense of the slower form is observed after overexpression of cyclin $E$ (Fig. 4C, cf. lanes 1 and 4). The invariant ratio between the two Dmcdc2c forms during $G_{2}, S$, and $M$ phase (Fig. $4 \mathrm{~A}$ ) argues that the amount of the complex formed by cyclin $\mathrm{E}$ and Dmcdc2c is also constant during the early embryonic division cycles.

A number of observations indicated that cyclin $E$ is the major partner of Dmcdc2c kinase. In DmcycE-deficient 

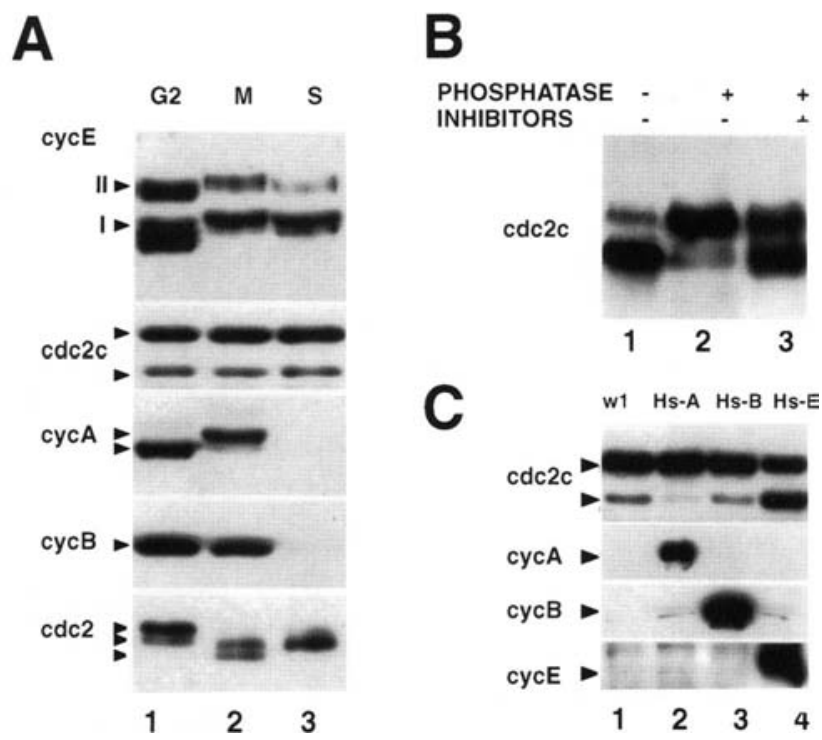

Figure 4. Cyclin $\mathrm{E}$ and Dmcdc2c kinase during the embryonic division cycle. $(A)$ Equal amounts of synchronized embryos /see Materials and methods) in $G_{2}$ (lane 1 ), early $M$ (prophase and metaphase; lane 2), or early $S$ phase (lane 3 ) were probed by immunoblotting with monoclonal antibodies against cyclin $\mathrm{E}$ (cycE), Dmcdc2c kinase (cdc2c), cyclin A (cycA), cyclin B (cycB), and Dmcdc2 kinase (cdc2). The different cyclin $\mathrm{E}$ proteins (Richardson et al. 1993), type I (arrowhead I) and type II (arrowhead II), are present during the $G_{2}$ phase and are not degraded during mitosis in contrast to cyclins $\mathrm{A}$ and $\mathrm{B}$. The ratio of different Dmcdc2c kinase forms does not vary during the division cycle in contrast to the ratio of the different Dmcdc2 kinase forms (see also Edgar et al. 1994). (B) Dmcdc2c kinase coprecipitated by anti-cyclin $\mathrm{E}$ antibodies was incubated in buffer only (lane 1) or in buffer containing potato acid phosphatase either without (lane 2) or with phosphatase inhibitors (lane 3). Dmcdc2c kinase forms were detected after SDS-PAGE and immunoblotting with a monoclonal anti-Dmcdc2c antibody. Phosphatase treatment converts the high mobility form of Dmcdc2c kinase, which is enriched in cyclin E complexes (Knoblich et al. 1994), into the low mobility form. (C) Cyclins A, B, and $\mathrm{E}$ were overexpressed in Drosophila embryos from $\mathrm{Hs}-\mathrm{cy}$ clin $A$ (lane 2), $H s-c y c l i n B$ (lane 3), or $H s-c y c l i n E$ (lane 4) transgenes and analyzed by immunoblotting with antibodies against Dmcdc2c kinase (cdc2c), cyclin A (cycA), cyclin B (cycB), and cyclin E (cycE). The comparison with heat shocked $w^{1}$ control embryos carrying no $H s-c y c l i n$ transgene (lane 1) indicates that cyclin $\mathrm{E}$ overexpression results in an enrichment of the high mobility form of Dmcdc2c kinase in contrast to cyclin A and B overexpression. Immunoblotting with the anticyclin antibodies detects predomininantly the transgene-derived products. At the late stages selected for the experiments (stage 13), the endogenous cyclin genes are expressed only in a very limited number of cells (Lehner and O'Farrell 1990a; Knoblich et al. 1994). In contrast, the $H s-c y c l i n$ transgenes are expressed in all embryonic cells. These also still contain Dmcdc2c kinase.

embryos, at the stage where phenotypic abnormalities start to become apparent (Knoblich et al. 1994), not only cyclin E-associated kinase activity but also Dmcdc2cassociated kinase activity was found to be strongly reduced (Fig. 5A). Moreover, immunodepletion experi- ments revealed that anti-cyclin $\mathrm{E}$ antibodies depleted Dmcdc2c kinase activity almost quantitatively from embryonic extracts (Fig. 5B), and anti-Dmcdc2c antibodies depleted cyclin $\mathrm{E}$-associated $\mathrm{H} 1$ kinase activity (Fig. 5C). Finally, cyclin E- and Dmcdc2c-associated kinase activities were found to have the same developmental profile during embryogenesis (Fig. 5D).

\section{Cyclin E/Dmcdc2c kinase is active during the $G_{2}$ phase}

To measure Dmcdc2c kinase activity during $\mathrm{S}, \mathrm{G}_{2}$, and $M$ phase of the embryonic division cycle, we synchronized cells by expressing $H s$-string during the $\mathrm{G}_{2}$ phase after cellularization. $\mathrm{Hs}$-string-induced mitosis was accompanied by the characteristic mitosis-specific modification and degradation of cyclin $\mathrm{A}$ as revealed by immunoblotting (Fig. 6A, cycA). Dmcdc2 kinase activity displayed the expected maximum during the $G_{2} / M$ transition (Fig. 6A, cdc2 HIP). In contrast, Dmcdc2c- and cyclin $\mathrm{E}$-associated kinase activity were found to be high throughout $\mathrm{G}_{2}, \mathrm{M}$, and $\mathrm{S}$ phase (Fig. 6A, cdc2c H1P and cycE HIP).

Compared with previous immunoblotting experiments (Fig. 5A), cell synchrony was compromised during Dmcdc2c activity measurements (Fig. 6A). Twenty-five percent of the embryos were lacking a $\mathrm{Hs}$-string transgene insertion, and this asynchronous contamination could not be excluded by microscopic selection, because the fixation used for the immunoblotting experiments destroys kinase activity (for details, see Materials and methods). To confirm that cyclin E/Dmcdc2c kinase remains active in the $G_{2}$ phase, we selected unfixed embryos during either cellularization (stage 5) or the early stages of germ-band extension (stage 6). BrdU pulse-labeling at these stages confirmed that the cells of cellularizing embryos were in $\mathrm{S}$ phase and the cells of embryos at early germ-band extension in $\mathrm{G}_{2}$ phase (Fig. 6B). Dmcdc2c kinase activity was present at both stages and was even slightly higher during the $G_{2}$ phase (Fig. 6B, cdc2c $\mathrm{H}(\mathrm{P})$. Cyclin E-associated kinase activity displayed the same behavior (Fig. 6B, cycE H1P). By quantifying histone $\mathrm{Hl}$ kinase activities and normalizing to the amounts of immunoprecipitated proteins /quantified by using known amounts of bacterially produced proteins as standards in immunoblotting experiments), Dmcdc2c activity was found to be $\sim 20$-fold higher than Dmcdc2 activity during the $G_{2}$ phase.

\section{Conversion of mitotic cycles into endoreduplication cycles in cyclin A mutants}

Control mechanisms that prevent another round of DNA replication during the $\mathrm{G}_{2}$ phase of the mitotic cell cycle have been demonstrated (Blow and Laskey 1988; Blow 1993; Coverley et al. 1993). However, the underlying molecular mechanisms are not understood. Our demonstration of high levels of cyclin E/Dmcdc2c activity during the $\mathrm{G}_{2}$ phase of the embryonic division cycles indicates that inhibition of cyclin $\mathrm{E} / \mathrm{Dmcdc} 2 \mathrm{c}$ kinase activity is not an essential part of these mechanisms. The 
Figure 5. Dmcdc2c kinase activity is dependent on cyclin E. $|A|$ Extracts from DmcycE-deficient embryos (lanes 2,4,6,8) and control embryos (lanes $1,3,5,7$ ) were analyzed by immunoblotting for the presence of cyclin E (lanes 1,2) and Dmcdc2c kinase (lanes 3,4), and after immunoprecipitation for cyclin E-associated histone $\mathrm{Hl} \mathrm{ki-}$ nase activity (lanes 5,6) and Dmcdc2c-associated histone $\mathrm{Hl}$ kinase activity (lanes 7,8). Control experiments indicated that equal amounts of Dmcdc2c kinase were precipitated from DmcycE-deficient and control embryos (not shown). $(B)$ Extracts from wild-type embryos were prepared and depleted of cyclin E by sequential immunoprecipitation (for experimental details, see Materials and methods). Dmcdc2c-associated (solid bars) and cyclin E-associated (stippled bars) histone $\mathrm{Hl}$ kinase activities present in the first (lane 1), second (lane 2) and third (lane 3) supernatant are given in percent of the activities present in the starting extract (lane 0 ) and were found to decrease in parallel. $(C)$ Extracts from wild-type embryos were prepared and depleted of Dmcdc2c kinase by sequential immunoprecipitation (for experimental details, see Materials and methods). Dmcdc2c-associated (solid bars) and cyclin E-associated (stippled bars) histone $\mathrm{Hl}$ kinase activities present in the first (lane 1), second (lane 2), third (lane 3) and fourth (lane 4) supernatant are given in percent of the activities present in the starting extract (lane $0)$ and were found to decrease in parallel. $(D)$ Extracts from 0 - to 2-hr (lane 1), 2- to 6-hr (lane 2), and 6- to 14-hr (lane 3) embryos were analyzed by immunoblotting for the presence of cyclin $E$ (top) and Dmcdc2c kinase (cdc2c), or after immunoprecipitation for the presence of cyclin E-associated (cycE HIP) and Dmcdc2c-associated (cdc2c H1P) histone $\mathrm{Hl}$ kinase activity. Immunoprecipitations were done either in the absence (-peptide) or in the presence (+ peptide) of peptide competitor. The autoradiographs visualize the amount of $\left[{ }^{32} \mathrm{P}\right]$ phosphate incorporation into histone $\mathrm{Hl}$. The $D m c y c E$ gene encodes at least two different cyclin E forms (Richardson et al. 1993). The larger cyclin E type II form (cycE II, top) is provided maternally, and the smaller cyclin E type I form (cycE I, top) reflects zygotic expression (Richardson et al. 1993). In 0- to 2-hr
embryos (lane 1), all cells progress through syncytial division cycles, and in 2- to 6-hr embryos (lane 2), through cell division cycles. In 6- to 14 -hr embryos (lane 3), cells are either in a postmitotic $G_{1}$-phase $(\sim 85 \%)$, in mitotic cycles $(\sim 10 \%)$, or in endoreduplication cycles $(\sim 5 \%)$.

analysis of cyclin E expression and DNA replication in Drosophila cyclin A (DmcycA) mutant embryos suggests that $G_{2}$ cyclins might be involved in this control.

Initially, DmcycA-deficient mutants develop normally because of the presence of maternally contributed protein and mRNA stores (Lehner and O'Farrell 1989). These stores are exhausted before the sixteenth round of embryonic mitoses, and the cells in DmcycA mutant embryos do not progress through this mitosis 16 . By in situ hybridization, we found that the normal program of $D m c y c E$ expression continued in DmcycA mutant embryos (data not shown). In particular, we also observed characteristic DmcycE expression in the thoracic epidermis, which anticipates S phase 17 in this region (Knoblich et al. 1994). After BrdU pulse-labeling at the stage of $S$ phase 17, BrdU incorporation not only was observed in control (Fig. 7A,B) but also in DmcycA mutant embryos (Fig. 7C,D). Double-labeling of tubulin and DNA during the preceding stages confirmed that the thoracic cells in DmcycA mutants do not progress through mitosis between $S$ phase 16 and $S$ phase 17 (Lehner and $O^{\prime}$ Farrell 1990a; Lehner et al. 1991; data not shown). The failure of mitosis is also evident from the facts that the number of BrdU-labeled nuclei is twofold lower and that
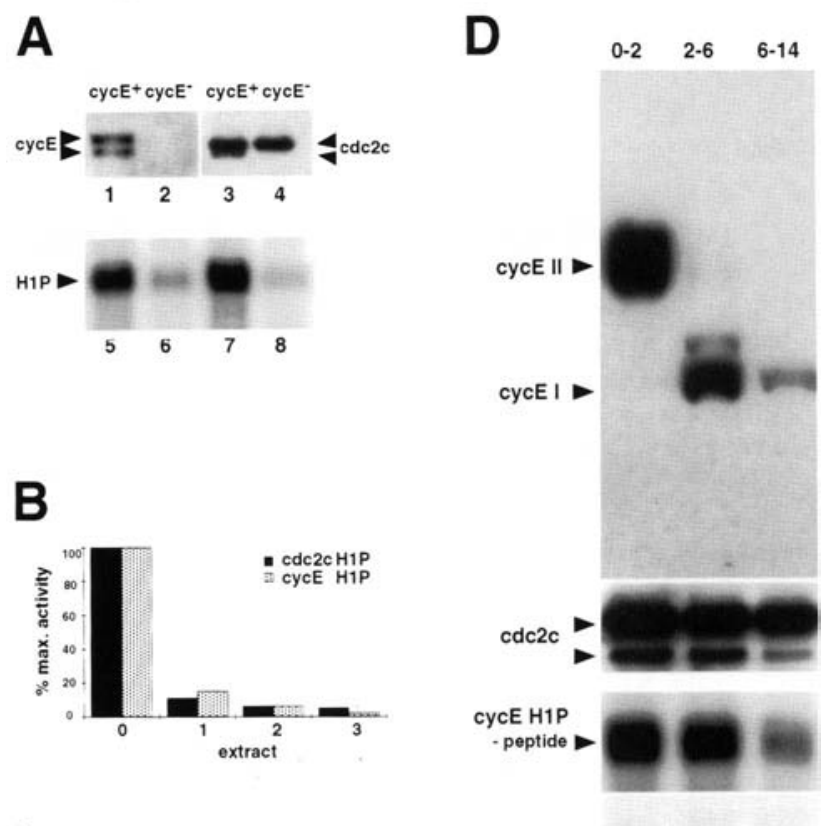

C
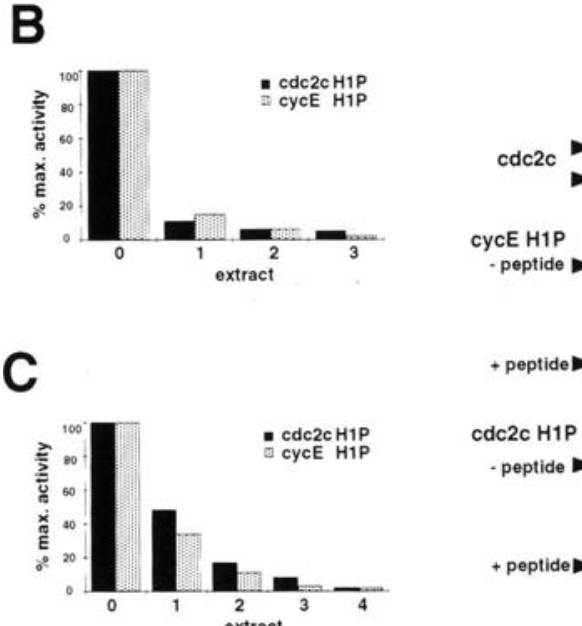

+ peptide es. . (n) 

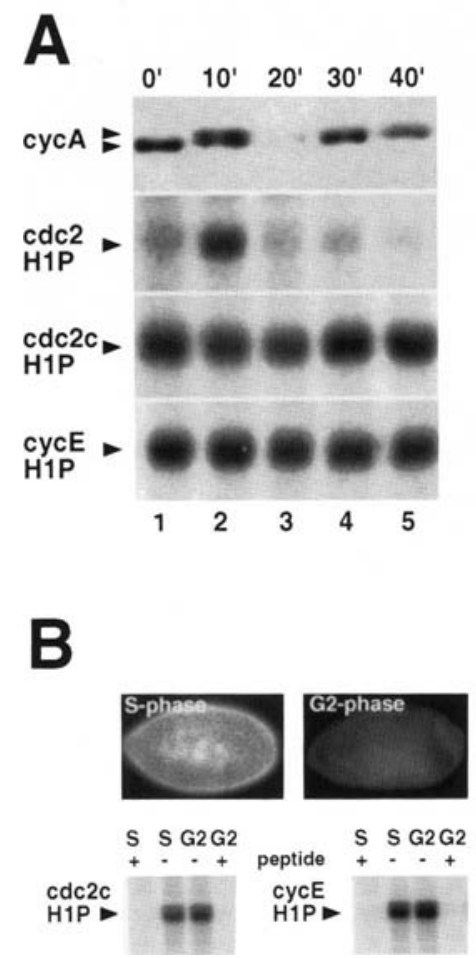

Figure 6. Cyclin E/Dmcdc2c kinase activity during the embryonic division cycle. $(A)$ Heat-induced expression from a $\mathrm{Hs}-$ string transgene was used to force cells synchronously into mitosis and into the following S phase (Edgar and O'Farrell 1990; for details, see Materials and methods|. Aliquots of embryos were taken prior to the heat pulse (lane 1 ), as well as $10 \mathrm{~min}$ (lane 2), $20 \mathrm{~min}$ (lane 3), $30 \mathrm{~min}$ (lane 4), and $40 \mathrm{~min}$ (lane 5) after the end of the heat shock. Cell cycle progression was monitored by immunoblotting with anti-cyclin A antibodies (cycA), which reveal a modified cyclin A form with lower electrophoretic mobility during prophase (lane 2) and the characteristic degradation during late mitosis (lane 3). Dmcdc2-associated (cdc2 H1P), Dmcdc2c-associated (cdc2c H1P), and cyclin E-associated (cycE $\mathrm{H} 1 \mathrm{P}$ ) histone $\mathrm{Hl}$ kinase activities were assayed after immunoprecipitations. Histone $\mathrm{Hl}$ kinase activity was visualized by autoradiography. Although Dmcdc2 kinase reveals the expected activity peak during the $\mathrm{G}_{2} / \mathrm{M}$ transition, cyclinE/Dmcdc2c kinase activity was constant. $(B)$ Embryos during stage 5 or 6 were either pulse-labeled with BrdU to confirm that stage 5 embryos are in $\mathrm{S}$ phase (top left) and stage 6 embryos in $\mathrm{G}_{2}$ phase (top right), or analyzed after immunoprecipitation for the presence of cyclin E-associated (cycE HIP) and Dmcdc2c-associated (cdc2c HlP) histone $\mathrm{Hl}$ kinase activity. Histone $\mathrm{Hl}$ kinase activity was visualized by autoradiography. The specificity of the immunoprecipitations was demonstrated by control experiments where the peptides used for immunizations were added as competitors. Peptide competition reduced the histone $\mathrm{HI}$ kinase activity in immunoprecipitations to background values (cf. - and + lanes).

cating tissues of Drosophila embryos (Knoblich et al. 1994). Endoreduplication occurs during wild-type embryogenesis in a defined tissue-specific and temporal pattern (Smith and Orr-Weaver 1991). Entry into endoreduplication $\mathrm{S}$ phases is preceded by a pulse of $D m c y c E$ tran- scription (Knoblich et al. 1994). Immunolabeling with antibodies against cyclin $\mathrm{E}$ indicates that protein levels follow mRNA levels (H. Richardson, L.V. O'Keefe, T. Marty, and R. Saint, in prep.). The onset of cyclin expression in endoreduplicating tissues is not dependent on cyclin E function, as it is also observed in DmcycE mutants. However, instead of being terminated rapidly the expression is maintained in DmcycE mutants. Thus, functional cyclin $E$ protein is required directly or indirectly to shut off its own expression. Consistent with this notion, we found that overexpression of cyclin $\mathrm{E}$ from a heat-inducible transgene down-regulates the endogenous DmcycE transcripts in endoreduplicating tissues.

A number of genes for products required during $\mathrm{S}$ phase $(D m R N R 1, D m R N R 2, P C N A, P O L \alpha)$ were recently found to display the same pattern of expression in endoreduplicating tissues as DmcycE (Duronio and O'Farrell 1994). Moreover, the transcription of these genes was shown to be induced by ectopic expression of cyclin E, suggesting that cyclin E might act as a master regulator of an S-phase-specific gene expression program (Duronio and O'Farrell 1994). The finding that mammalian cyclin $\mathrm{E}$ is found in transcription factor complexes (E2F and retinoblastoma protein families) controlling cell cycle genes also emphasizes an involvement in transcriptional control (Hinds et al. 1992; Lees et al. 1992; Li et al. 1993). Our observation that DmRNR2 expression is still initiated in DmcycE mutants demonstrates that the activation of this S-phase-specific gene expression program is not necessarily dependent on cyclin $\mathrm{E}$ function. At least in the endoreduplicating tissues, DmcycE expression appears to be downstream of a developmentally controlled regulator of the $G_{1} / S$ transition. On the basis of results obtained in vertebrates it is attractive to speculate that cyclin $D$ might be this regulator of the $G_{1} / S$ transition. While cyclin $\mathrm{E}$ function is not required for the activation of the $\mathrm{S}$ phase-specific gene expression program, it appears required for shutting it off, because not only $D m c y c E$ but also DmRNR2 expression is maintained in DmcycE mutants. Figure 8B includes one possible interpretation explaining our observations.

Our finding that the program of S-phase-specific gene expression is still initiated in DmcycE mutants, yet no DNA replication follows, suggests that cyclin $E$ has functions beyond transcriptional regulation of target genes. Nontranscriptional roles of cyclin $\mathrm{E}$ are also suggested by the fact that high levels of cyclin $E$ and associated kinase activity are detected during the very early, syncytial cycles of Drosophila embryogenesis (Fig. 5D) that proceed in complete absence of transcription.

\section{Cyclin E/cdc2c kinase activity is constant during early embryonic division cycles}

The control of DmcycE expression in mitotically proliferating cells is different from that observed in endoreduplicating tissues. Whereas $D m c y c E$ transcripts are elevated in those tissues of $D m c y c E$ mutant embryos that correspond to endoreduplicating tissues of wild-type em- 
Figure 7. Inappropriate endoreduplication in DmcycA mutant embryos. Control embryos $(A, B)$ and homozygous $D m c y c A$ mutant embryos $(C, D)$ were pulse-labeled with BrdU for 15 min at stage 12 of embryogenesis. $B$ and $D$ show the regions indicated by white frames in $A$ and $C$ at higher magnification. The labeling in these regions reflects $\mathrm{BrdU}$ incorporation during $\mathrm{S}$ phase 17. $S$ phase 17 is also observed in DmcycA mutants in which the cells do not progress through mitosis 16 , a finding that is also reflected by reduced number and larger size of the labeled nuclei present in the $D m$ cycA mutants (cf. $B$ and $D$ ).
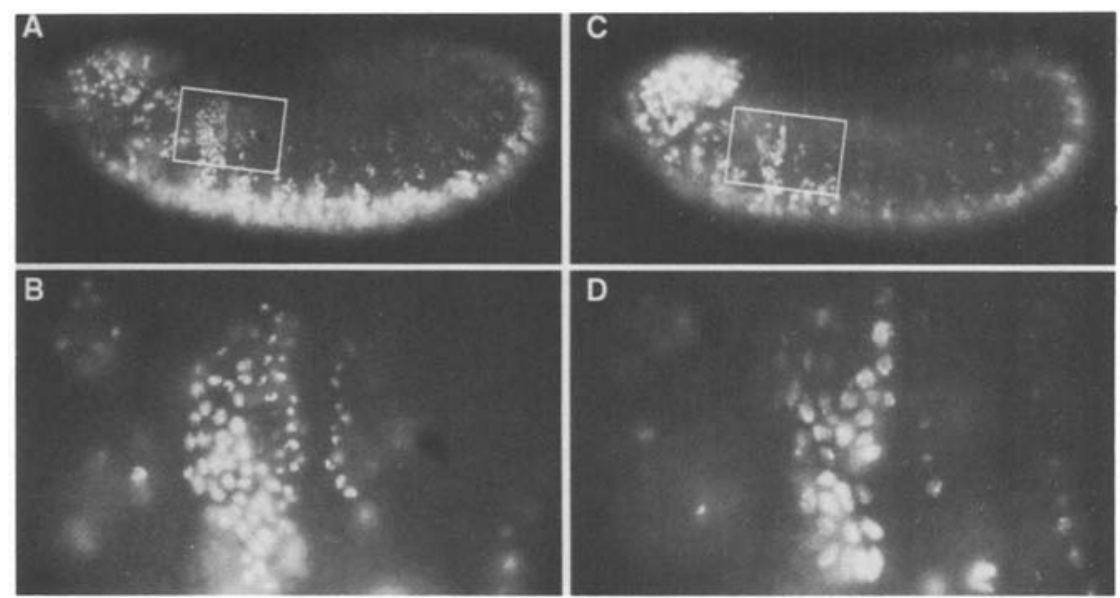

bryos, they are strongly reduced in the $D m c y c E$ mutant nervous system that proliferates mitotically in wild-type embryos. In addition, DmRNR2 and cyclin A and B expression were found to be almost absent in the nervous system of late DmcycE mutants (Fig. 2; J.A. Knoblich and C.F. Lehner, unpubl.). The decline of DmRNR2 and cyclin A, B, and E transcript levels in DmcycE mutants, however, starts at stage 13 clearly after the cell cycle arrest that follows the exhaustion of the maternal cyclin $E$ contribution at stage 12 . The reduced expression of cyclin A, B, and E might therefore be an indirect consequence of the cell cycle arrest.

The negative feedback loop in which cyclin $\mathrm{E}$ terminates $D m c y c E$ expression in endoreduplicating tissues is not observed in mitotically proliferating cells. In these cells, cyclin E expression is not limited to a pulse at the beginning of $S$ phase. Our immunofluorescence and immunoblotting experiments clearly demonstrate that cyclin $\mathrm{E}$ as well as its major kinase partner, which in Drosophila is encoded by the Dmcdc2c gene (Lehner and O'Farrell 1990b; Knoblich et al. 1994), are both present predominantly in the nucleus throughout the embryonic division cycle. Moreover, the activity of the cyclin
$\mathrm{E} / \mathrm{cdc} 2 \mathrm{c}$ kinase complex is essentially constant during these cycles. The continuous presence of cyclin $\mathrm{E} / \mathrm{cdc} 2 \mathrm{c}$ kinase activity is correlated with the absence of $G_{1}$ phases during the embryonic division cycles and presumably causes immediate entry into $S$ phase after each mitosis (Edgar and O'Farrell 1990; Knoblich et al. 1994).

Many of our experiments involved a heat pulse for synchronization of cell cycle progression in string, $\mathrm{Hs}-$ string embryos. Strong heat shocks have been shown to block progression through S phase in Drosophila embryos (Maldonado-Codina et al. 1993). Even our mild heat pulses were found to cause strong reduction of the cyclin $\mathrm{E}$ form with the highest mobility. We emphasize, however, that the presence of high cyclin $\mathrm{E} / \mathrm{cdc} 2 \mathrm{c}$ kinase activity during the $G_{2}$ phase was also found in experiments that did not involve a heat pulse (Fig. 6B). That this activity is unlikely to be caused artifactually by release of cyclin-dependent kinase inhibitors is suggested by the fact that the inhibitors, which recently have been identified, associate tightly with their targets and are not released during immunoprecipitations (Gu et al. 1993; Harper et al. 1993; Serrano et al. 1993; Xiong et al. 1993; Peter and Herskowitz 1994; Polyak et al. 1994; Schnei-
Figure 8. A model for the conversion of mitotic cycles into endoreduplication cycles. Cyclin $\mathrm{E}$, which is constant during the embryonic division (mitotic) cycle $(A)$ and periodic during the endoreduplication cycle $(B)$, is required for $S$ phase in both cell cycle types. Periodic expression in endoreduplicating cells involves a negative feedback loop (in which cyclin $\mathrm{E}$ terminates its own expression). Periodic expression results in periodic $S$ phases because cyclin $\mathrm{E}$ expression is sufficient to trigger $S$ phase in endoreduplicating tissues (Knoblich et al. 1994). In contrast, cyclin $\mathrm{E}$ is not sufficient to trigger $S$ phase during the $G_{2}$ phase of the mitotic cycle. This inhibition of endoreduplication during the $G_{2}$ phase appears to be dependent on $G_{2}$ cyclin accumulation. Conversion of the mitotic cycle into an endoreduplication cycle therefore requires the termination of $\mathrm{G}_{2}$ cyclin transcription and activation of the negative cyclin E feedback loop. Processes incompatible with a given cell cycle type are shaded (for further details, see text).

\section{A}
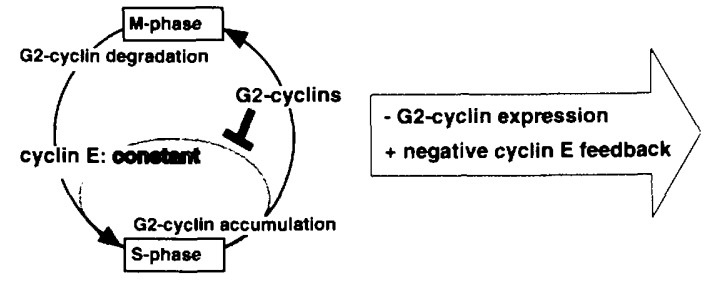

periodic S-phase alternating with M-phase
B

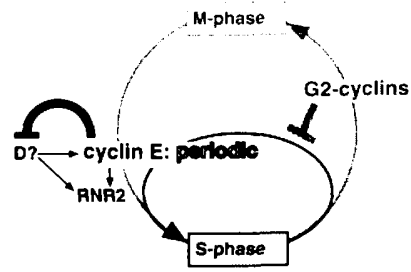

periodic S-phase

without intervening M-phase 
der et al. 1994; Slingerland et al. 1994; Toyoshima and Hunter 1994).

\section{Cyclin $A$ is required to maintain the block of rereplication during the $G_{2}$ phase}

The observation that cyclin $\mathrm{E} / \mathrm{cdc} 2 \mathrm{c}$ kinase remains active during the $G_{2}$ phase of the embryonic division cycles indicates that the mechanism preventing inappropriate endoreduplication during the $G_{2}$ phase is not dependent on the inactivation of this kinase. Our observations in cyclin A mutant embryos, however, implicate cyclin A in this control mechanism.

In Drosophila embryos, cyclin A is found in complexes with the cdc2 kinase but not with the cdc2c kinase (Knoblich et al. 1994). Moreover, phenotypic characterization of $D m c y c A$ mutant embryos suggests that cyclin $\mathrm{A}$ is essential for mitosis but not for $\mathrm{S}$ phase. Mitotic divisions, at least in the epidermis where they can be readily monitored, stop in DmcycA mutant embryos after the exhaustion of the maternally provided cyclin A mRNA and protein stores (Lehner and O'Farrell 1990a; Knoblich and Lehner 1993). DNA replication, however, continues in DmcycA mutants (Fig. 7; Lehner et al. 1991). BrdU incorporation not only continues in tissues where endoreduplication occurs during wild-type embryogenesis but also in regions (predominantly in the nervous system) that continue to proliferate mitotically in late wildtype development.

The detailed analysis of a region in the thoracic epidermis that progresses through a seventeenth mitotic cycle during wild-type embryogenesis indicates that mitotic cycles are transformed into endoreduplication cycles in DmcycA mutants. In this thoracic region, $\mathrm{S}$ phase 17 was found to follow after S phase 16 in $D m c y c A$ mutants despite the absence of mitosis 16 , which normally separates these two $S$ phases during wild-type development. We assume that the BrdU incorporation, which is observed in the nervous system of late $D m c y c A$ mutants (Lehner et al. 1991), also results from progression through endoreduplication cycles instead of mitotic cycles. For technical reasons, it is difficult to monitor cell cycle progression in internal tissues like the nervous system; therefore, we cannot rule out the possibility of occasional mitoses in the $D m c y c A$ mutant nervous system. In the case of the thoracic region, however, tubulin and DNA labeling failed to reveal mitotic spindles and chromosome figures in $D m c y c A$ mutants between $\mathrm{S}$ phase 16 and 17 , and the failure of mitosis 16 was also evidenced by the reduced cell number and increased cell size. Thus, at least in the case of the thoracic region, our observations indicate that cyclin $\mathrm{A}$ is required to maintain the physiological block of DNA replication that prevents rereplication during the $G_{2}$ phase of the mitotic cycle.

A number of experiments (J.A. Knoblich and C.F. Lehner, unpubl.) suggest that cyclin $A$ and $B$ expression is not sufficient to prevent endoreduplication. Ectopic cyclin A and B expression from a heat-inducible transgene does not prevent endoreduplication in endoreduplicating tissues. Moreover, whereas ectopic cyclin E expression immediately after $S$ phase 16 can force all epidermal cells of DmcycA mutant embryos into an additional second $S$ phase without an intervening mitosis 16 , the entry into this second $S$ phase does not occur immediately after $S$ phase 16 but, interestingly, at about the stage where cyclins B and B3 are no longer detectable in the epidermal cells of DmcycA mutants. Cyclin B3 is an evolutionary conserved cyclin type of higher eukaryotes (Gallant and Nigg 1994; Kreutzer et al. 1995) that recently has been identified in Drosophila (J.A. Knoblich and C.F. Lehner, unpubl.). Like cyclin B, cyclin B3 accumulates in $D m c y c A$ mutants before mitosis 16 and disappears again from the epidermal cells despite the failure of mitosis 16 (Lehner and O'Farrell 1990a). At present, we do not understand the reasons for the disappearance of B-type cyclins, which occurs quite rapidly at the stage where the epidermal cells normally progress through mitosis 16 in wild-type embryos. We cannot exclude that the cells in cyclin A mutants progress through a cryptic mitosis that does not involve mitotic spindle formation and chromosome condensation but does involve some degradation of $G_{2}$ cyclins. The presence of cyclin B3 in cyclin A/B double mutants could also explain why endoreduplication (which does occur in late cyclin A/B double mutants/ does not start prematurely at the stage where cells would normally proliferate mitotically. Drosophila cyclin B3, in contrast to cyclins A and B, accumulates in the nucleus; therefore, an attractive speculation is that cyclin B3 is involved in inhibiting inappropriate endoreduplication during the $G_{2}$ phase of the mitotic cell cycle. However, verification of this hypothesis would require the isolation of cyclin B3 mutations.

The abnormal endoreduplication observed in $D m c y c A$ mutants is reminiscent of the endoreduplication that has been observed recently in fission yeast strains unable to express the B-type cyclin encoded by the $c d c 13$ gene (Hayles et al. 1994). Interestingly, the over-replication observed in these fission yeast mutants apparently occurs in distinct rounds, as clear peaks of cells with multiples of the normal DNA content are resolved by FACS analysis (Hayles et al. 1994). B-type cyclins other than p56 $6^{\text {cdc13 }}$ are known in fission yeast (Bueno et al. 1991; Bueno and Russell 1993; Connolly and Beach 1994), and these cyclins might also be removed in the $c d c 13$ mutant strains during cryptic mitoses without spindle formation and chromosome condensation. Although far from being understood in detail, our observation in $D m c y c A$ mutants as well as the observations in $c d c 13$ mutant fission yeast suggest that $G_{2}$ cyclins might not only be required for entry into mitosis but also for preventing inappropriate endoreduplication during the $\mathrm{G}_{2}$ phase of the mitotic cell cycle.

\section{Converting the mitotic cell cycle into an endoreduplication cycle}

Our observations concerning the regulation of mitotic and endoreduplication cycles during Drosophila embryo- 
genesis are consistent with the model illustrated in Figure 8. Cyclin $\mathrm{E}$ appears to trigger $\mathrm{S}$ phase both in mitotically proliferating cells and endoreduplicating cells. As suggested previously (Knoblich et al. 1994; see also Amon et al. 1994), cyclin E expression also results in the inactivation of $\mathrm{G}_{2}$ cyclin degradation in mitotically proliferating cells and thus permits $G_{2}$ cyclin accumulation. $\mathrm{G}_{2}$ cyclins would then prohibit induction of a second $S$ phase by cyclin E/cdc2c kinase activity, which is still present during the $G_{2}$ phase. In addition, $G_{2}$ cyclins would also allow entry into $M$ phase, and the activation of $\mathrm{G}_{2}$ cyclin degradation during mitosis would reset the cycle. The conversion of such a mitotic cycle into an endoreduplication cycle could be achieved by abolishing the transcription of $G_{2}$ cyclin genes and by expressing cyclin $\mathrm{E}$ in pulses to trigger periodic $S$ phases. Absence of $\mathrm{G}_{2}$ cyclin expression in endoreduplicating tissues has been reported previously (Lehner and O'Farrell 1989, 1990a), and here, a negative feedback loop restricting cyclin $\mathrm{E}$ expression in endoreduplicating tissues to pulses is reported.

The confirmation of this model will require additional analyses, and biochemical details will be more accessible in other experimental systems. The model, however, emphasizes that the rapid progress in the understanding of mitotic cell cycle regulation, which has been achieved in recent years, provides a basis for an understanding of endoreduplication as well. Cyclin $\mathrm{E}$ is clearly important for S-phase control in both mitotic and endoreduplication cycles which, although not normally observed in yeast and rarely in vertebrates, are of very widespread occurrence. The generation of the vast majority of the eukaryotic biomass on earth is associated with progression through endoreduplication cycles, as these are very common in plants and insects. Studies with Drosophila will allow a further comparison of the regulation of mitotic and endoreduplication cycles.

\section{Materials and methods}

Fly stocks

The fly stocks used in this study have all been described previously. Transgenic stocks allowing the expression of cyclin A (Hs-cyclin A), B (Hs-cyclin B), or E (Hs-cyclin E) or the String/ Cdc25 phosphatase (Hs-string) under the control of a heat-inducible heat shock promoter have been described in Knoblich and Lehner (1993), Knoblich et al. (1994), and Edgar and O'Farrell (1990). As these heat-inducible transgenes were established in the white mutant background, we used the white stock for control experiments. Stocks with mutations in $D m c y c A$, $D m c y c E$, or string have been described in Lehner and O'Farrell (1989), Knoblich et al. (1994), and Edgar and O'Farrell (1989).

\section{In situ hybridization}

In situ hybridization was performed as described by Knoblich et al. (1994). To generate a cyclin E probe that detected transcripts derived from the endogenous $D m c y c E$ gene but not from the $H s$-cyclin $E$ transgene, we cloned a region of the 3 '-untranslated region (nucleotides 2965-3870 of cyclin E cDNA type I, numbered as in Richardson et al. 1993), which is not present in the
$H s-c y c l i n E$ transgene, into Bluescript $\mathrm{KS}+$ and used the resulting plasmid as a template for transcription of antisense RNA in the presence of digoxygeninylated UTP /Boehringer Mannheim). Endogenous $D m c y c E$ as well as $H s-c y c l i n E$ transcripts were detected with a digoxygeninylated antisense RNA probe derived from the coding region of cyclin $\mathrm{E}$ (amino acids 193-517 of cyclin E type I, numbered as in Richardson et al. 1993). A plasmid containing a DmRNR2 cDNA (Duronio and O'Farrell 1994) was used for the production of a DmRNR2 antisense RNA probe.

To identify the homozygous $D m c y c E$ mutant embryos among the progeny of heterozygous parents, we combined in situ hybridization with BrdU pulse-labeling. In contrast to their siblings, homozygous DmcycE mutant embryos no longer incorporate BrdU after stage 12 (Knoblich et al. 1994). Before fixation, therefore, we permeabilized the embryos and labeled during a 15-min pulse with BrdU, as described previously (Edgar and O'Farrell 1990; Lehner et al. 1991). Detection of incorporated BrdU after in situ hybridization was done as described by Richardson et al. (1993), except that immunofluorescence instead of immunocytochemical detection was used.

\section{BrdU pulse-labeling and immunofluorescence}

For analysis of DNA replication in DmcycA mutants, we collected eggs from a stock carrying the $D m c y c A^{3}$ allele (synonym 1(3)183) over the balancer chromosome $T M 3, \mathrm{P}\left[\mathrm{w}^{+}, U b \mathrm{U}-\mathrm{lacZ}\right]$, which carries a transgene directing the expression of $\beta$-galactosidase. The $D m c y c A^{3}$ allele is a small deficiency that deletes the DmcycA gene completely (Lehner et al. 1991). Homozygous mutants could be identified based on the absence of $\beta$-galactosidase expression. Pulse-labeling with $\mathrm{BrdU}\left(15 \mathrm{~min}\right.$ at $\left.25^{\circ} \mathrm{C}\right)$, followed by fixation and double labeling with antibodies against $\mathrm{BrdU}$ and $\beta$-galactosidase, was done as described previously (Edgar and O'Farrell 1990; Lehner et al. 1991).

For the immunofluorescent localization of Dmcdc2c kinase and cyclin $\mathrm{E}$, we used affinity-purified rabbit antibodies against carboxy-terminal peptides (Knoblich et al. 1994) as well as mouse monoclonal antibodies (Knoblich et al. 1994; H. Richardson, in prep.) as described by Lehner and O'Farrell (1989). Peptide competition experiments were done to control for specificity in the case of anti-peptide antibodies. For antibody against the carboxyl terminus of Dmcdc2c kinase, we added the Dmcdc2c carboxy-terminal peptide (Knoblich et al. 1994) as a specific competitor or the Dmcdc2 carboxy-terminal peptide (Knoblich et al. 1994) as a nonspecific competitor, both at a final concentration of $0.1 \mathrm{mg} / \mathrm{ml}$ during incubation with the primary antibody. Double labeling with DNA stain Hoechst 33258 was done as described previously (Lehner and O'Farrell 1989).

\section{Immunoblotting}

The stock $w$; string ${ }^{7 B}, \mathrm{P}\left[\mathrm{w}^{+}, H s-\right.$ string $] / T M 3$ was used to analyze the levels of the various cyclin $E$ and $c d c 2 c$ kinase forms at different stages of the embryonic division cycle by immunoblotting. Eggs were collected on apple agar plates for $30 \mathrm{~min}$ and aged for $180 \mathrm{~min}$ at $25^{\circ} \mathrm{C}$. Fixation, Hoechst 33258 staining, and storage of embryos at $-70^{\circ} \mathrm{C}$ were done as described by Edgar et al. (1994). These conditions allow selection of embryos with all cells in the desired cell cycle phase under an inverted microscope and subsequent solubilization in SDS gel sample buffer. For the preparation of $G_{2}$ extracts, we selected and pooled string ${ }^{7 B}, \mathrm{P}\left[\mathrm{w}^{+}, H\right.$ s-string $] /$ string $^{7 B}, \mathrm{P}\left[\mathrm{w}^{+}, H\right.$ s-string $]$ embryos, where all cells were arrested in the $G_{2}$ phase of cycle 14. For preparations of early mitotic extracts (prophase and metaphase) or early S-phase extracts, we floated the collection plates for 15 
min on a $37^{\circ} \mathrm{C}$ water bath to express the $H s$-string transgene before recovery at $25^{\circ} \mathrm{C}$ and fixation. Subsequently, string ${ }^{7 B}$, $\mathrm{P}\left[\mathrm{w}^{+}, H s\right.$-string $] /$ string $^{7 B}, \mathrm{P}\left[\mathrm{w}^{+}, H\right.$ s-string $]$ embryos at the desired cell cycle stages were selected and pooled. Early mitotic stages were maximal after $13 \mathrm{~min}$ of recovery at $25^{\circ} \mathrm{C}$, and early S-phase stages after $19 \mathrm{~min}$.

Stocks carrying a $H s-c y c l i n A$, a $H s-c y c l i n B$, or a $H s-c y c l i n$ $E$ transgene were used to analyze the effect of cyclin protein overexpression on the level of the various forms of Dmcdc2c kinase. Eggs were collected for $1 \mathrm{hr}$ and aged for $18.5 \mathrm{hr}$ at $18^{\circ} \mathrm{C}$. A heat shock was applied by floating the collection plates for 30 min on a $37^{\circ} \mathrm{C}$ water bath. Embryos were collected after $45 \mathrm{~min}$ of recovery at $25^{\circ} \mathrm{C}$, dechorionated, and solubilized in SDS gel sample buffer.

SDS-PAGE and immunoblotting were done as described by Knoblich and Lehner (1993). The amount of embryos used for extract preparation was determined either by counting individual embryos or by determining the volume of the dechorionated embryos sedimented in a microcapillary tube prior to homogenization. Antibodies against cyclin A, B, and E and Dmcdc 2 and Dmcdc2c kinase have also been described previously (Lehner and O'Farrell 1989; Knoblich and Lehner 1993; Knoblich et al. 1994). For quantification, we resolved serial dilutions of a mixture of bacterial extracts containing known amounts of Drosophila cyclins $\mathrm{A}, \mathrm{B}$, and $\mathrm{E}$, as well as Dmcdc2 and Dmcdc2c protein on the same gel along with the extracts. After immunoblotting, we estimated the concentration of the respective antigens in the extracts by using the signals obtained with these serial dilutions as standards (data not shown).

\section{Immunoprecipitations and histone $H 1$ kinase assays}

Immunoprecipitations and histone $\mathrm{Hl}$ kinase assays of immunoprecipitated material were performed as described by Knoblich et al. (1994), except that instead of autoradiography a PhosphorImager (Molecular Dynamics) was used for visualization and quantification of ${ }^{32} \mathrm{P}$ incorporation into histone $\mathrm{H} 1$ in some cases. Extracts were normalized to contain equal numbers or equal volumes of embryos. Phosphatase treatment of Dmcdc2c kinase coprecipitated by anti-cyclin $\mathrm{E}$ antibodies was done essentially as described by Edgar et al. (1994), with the following modifications: Prewashed immunoprecipitates were incubated for $40 \mathrm{~min}$ at $37^{\circ} \mathrm{C}$ with 4 units of sweet potato acid phosphatase (Sigma) in $40 \mu \mathrm{l}$ of buffer. Where indicated, incubations also contained $3 \mathrm{mM} \mathrm{Na}_{3} \mathrm{VO}_{4}$ to inhibit the phosphatase. Reactions were stopped by addition of $40 \mu$ l of gel loading buffer, containing $80 \mathrm{mM}$ Na- $\beta$-glycerophosphate, $20 \mathrm{~mm}$ EGTA, $2 \mathrm{~mm}$ $\mathrm{Na}_{3} \mathrm{VO}_{4}, 50 \mathrm{~mm} \mathrm{NaF}, 1 \mathrm{mM} \mathrm{Na}$-meta-bisulfite, $0.2 \mathrm{mM}$ PMSF, 1 $\mathrm{mM}$ benzamidine, and subsequent boiling for $10 \mathrm{~min}$.

To analyze Dmcdc2c- and cyclin E-associated histone $\mathrm{Hl} \mathrm{ki-}$ nase activity during the embryonic division cycle we used a stock with the $\mathrm{Hs}$-string transgene. All $\mathrm{Hs}$-string transgenes result in recessive lethality; therefore, a heterozygous stock (Hs-string/TM3) had to be used. Eggs were collected for $15 \mathrm{~min}$ and aged for $165 \mathrm{~min}$ at $25^{\circ} \mathrm{C}$. After a 17.5 -min heat shock (see above), embryos were returned to $25^{\circ} \mathrm{C}$. Aliquots were taken just prior to the heat shock and after 10, 20,30, and 40 min of recovery at $25^{\circ} \mathrm{C}$. Extracts were prepared and used for analysis by immunoblotting and by immunoprecipitation and histone H1 kinase assays.

To analyze Dmcdc2c- and cyclin E-associated histone $\mathrm{Hl} \mathrm{ki-}$ nase during either $S$ phase 14 or $G_{2}$ phase 14 , wild-type eggs were collected for $1 \mathrm{hr}$ and aged for $2 \mathrm{hr}$. After dechorionization, we selected embryos that were either at stage 5 or 6 with the help of a dissection microscope. Embryos at the corresponding stages were pooled on ice before immunoprecipitation and his- tone $\mathrm{Hl}$ kinase assays. In a parallel experiment, we pulse-labeled an analogous egg collection for $10 \mathrm{~min}$ with BrdU to confirm that stage 5 embryos are in $S$ phase 14 and stage 6 embryos are in $\mathrm{G}_{2}$ phase 14 .

To analyze Dmcdc2c- and cyclin E-associated histone $\mathrm{Hl}$ kinase in $D m c y c E$ mutant embryos, we used the stock $D f(2 L) 35 D-1 /$ CyO, $\mathrm{P}\left[\mathrm{w}^{+}, f t z-l a c Z\right]$. The deficiency $D f(2 L) 35 D-1$ deletes not only the DmcycE gene but also the snail gene (Knoblich et al. 1994), which encodes a zinc finger transcription factor required for normal gastrulation. Homozygous deficient embryos $16-8 \mathrm{hr}$ after egg deposition at $25^{\circ} \mathrm{C}$ ) could therefore be selected on the basis of the snail mutant phenotype, which is readily detectable under the dissection microscope after dechorionization. Homozygous deficient or control embryos were pooled on ice before homogenization, immunoprecipitation, and histone $\mathrm{Hl}$ kinase assays were performed. Additional experiments with snail mutant embryos indicated that the snail phenotype is not associated with an arrest of cell cycle progression (data not shown).

For immunodepletion of Dmcdc2c by sequential immunoprecipitations, we collected embryos for $75 \mathrm{~min}$ and aged them for $165 \mathrm{~min}$ at $25^{\circ} \mathrm{C}$. Starting extracts were prepared from $\sim 500$ embryos. An aliquot corresponding to 50 embryos was used for immunoprecipitation with anti-cyclin $\mathrm{E}$ antibodies to determine the cyclin $\mathrm{E}$-associated histone $\mathrm{Hl}$ kinase activity in the starting extract. Dmcdc2c kinase was depleted from the rest of the extract by immunoprecipitation. An aliquot of the immunoprecipitate corresponding to 50 embryos was used to determine the Dmcdc2c-associated histone $\mathrm{Hl}$ kinase activity in the starting extract. From the supernatant obtained after this first immunodepletion with anti-Dmcdc2c antibodies, we again removed an aliquot corresponding to 50 embryos for determination of residual cyclin $\mathrm{E}$-associated histone $\mathrm{H} 1$ kinase activity. The rest of the supernatant was used for the second immunodepletion with anti-Dmcdc2c antibodies, and an aliquot of the immunoprecipitate corresponding to 50 embryos was used for determination of the Dmcdc2c-associated histone $\mathrm{Hl}$ kinase activity present in the supernatant obtained after the first immunodepletion. The procedure was repeated for a total of four rounds of immunodepletion. Immunodepletion with anti-cyclin $\mathrm{E}$ antibodies was done similarly except that only three rounds were completed. In all immunoprecipitations, we used $0.7 \mu \mathrm{g}$ of antibody per embryo. For quantitation, we subtracted the counts obtained from immunoprecipitations with peptide competition from the counts obtained without peptide competition, and the activities were calculated as percent of the activity found in the starting extract.

\section{Acknowledgments}

Eva Maria Illgen and Jürgen Beckhoff provided invaluable technical help. We thank Bob Duronio and Pat $\mathrm{O}^{\prime}$ Farrell for providing the DmRNR2 cDNA and sharing information prior to publication, and members of our laboratory for comments on the manuscript.

The publication costs of this article were defrayed in part by payment of page charges. This article must therefore be hereby marked "advertisement" in accordance with 18 USC section 1734 solely to indicate this fact.

\section{References}

Amon, A., M. Tyers, B. Futcher, and K. Nasmyth. 1993. Mechanisms that help the yeast cell cycle clock tick: G2 cyclins 
transcriptionally activate G2 cyclins and repress G1 cyclins. Cell 74: 993-1007.

Amon, A., S. Irniger, and K. Nasmyth. 1994. Closing the cell cycle circle in yeast: $\mathrm{G} 2$ cyclin proteolysis initiated at mitosis persists until the activation of Gl cyclins in the next cycle. Cell 77: 1037-1050.

Baldin, V., J. Lukas, M.J. Marcote, M. Pagano, and G. Draetta. 1993. Cyclin D1 is a nuclear protein required for cell cycle progression in $\mathrm{G}_{1}$. Genes \& Dev. 7:812-821.

Blow, J.J. 1993. Preventing re-replication of DNA in a single cell cycle: evidence for a replication licensing factor. I. Cell Biol. 122: 993-1002.

Blow, J.J. and R.A. Laskey. 1988. A role for the nuclear envelope in controlling DNA replication within the cell cycle. Nature 332: 546-548.

Bueno, A. and P. Russell. 1993. Two fission yeast B-type cyclins, cig2 and cdcl3, have different functions in mitosis. Mol. Cell. Biol. 13: 2286-2297.

Bueno, A., H. Richardson, S.I. Reed, and P. Russell. 1991. A fission yeast B-type cyclin functioning early in the cell cycle. Cell 66: 149-159.

Connolly, T. and D. Beach. 1994. Interaction between the cigl and cig2 B-type cyclins in the fission yeast-cell cycle. Mol. Cell. Biol. 14: 768-776.

Coverley, D., C.S. Downes, P. Romanowski, and R.A. Laskey. 1993. Reversible effects of nuclear membrane permeabilization on DNA replication: evidence for a positive licensing factor. J. Cell Biol. 122: 985-992.

Cross, F.R. and A.H. Tinkelenberg. 1991. A potential positive feedback loop controlling CLN1 and CLN2 gene-expression at the start of the yeast-cell cycle. Cell 65: 875-883.

Dirick, L. and K. Nasmyth. 1991. Positive feedback in the activation of G1 cyclins in yeast. Nature 351: 754-757.

Duronio, R.J. and P.H. O'Farrell. 1994. Developmental control of a G1-S transcriptional program in Drosophila. Development 120: 1503-1515.

Edgar, B.A. and P.H. O'Farrell. 1989. Genetic control of cell division patterns in the Drosophila embryo. Cell 57: 177183.

- 1990. The three postblastoderm cell-cycles of Drosophila embryogenesis are regulated in G2 by string. Cell 62: 469-480.

Edgar, B.A., F. Sprenger, R.J. Duronio, P. Leopold, and P.H. O'Farrell. 1994. Distinct molecular mechanisms regulate cell cycle timing at successive stages of Drosophila embryogenesis. Genes \& Dev. 8: 440-452.

Enoch, T., A.M. Carr, and P. Nurse. 1992. Fission yeast genes involved in coupling mitosis to completion of DNA replication. Genes \& Dev. 6: 2035-2046.

Evans, T., E.T. Rosenthal, J. Youngblom, D. Distel, and T. Hunt. 1983. Cyclin: A protein specified by maternal mRNA in sea urchin eggs that is destroyed with each cleavage division. Cell 33: 389-397.

Fang, F. and J.W. Newport. 1991. Evidence that the Gl-S and G2-M transitions are controlled by different $\mathrm{cdc} 2$ proteins in higher eukaryotes. Cell 66: 731-742.

Gallant, P. and E.A. Nigg. 1994. Identification of a novel vertebrate cyclin: Cyclin B3 shares properties with both A-type and B-type cyclins. EMBO I. 13: 595-605.

Ghiara, J.B., H.E. Richardson, K. Sugimoto, M. Henze, D.J. Lew, C. Wittenberg, and S.I. Reed. 1991. A cyclin B homolog in Saccharomyces cerevisiae-Chronic activation of the cdc28 protein kinase by cyclin prevents exit from mitosis. Cell 65: 163-174.

Glotzer, M., A.W. Murray, and M.W. Kirschner. 1991. Cyclin is degraded by the ubiquitin pathway. Nature 349: 132-138.
Gu, Y., C.W. Turck, and D.O. Morgan. 1993. Inhibition of cdk2 activity in vivo by an associated $20 \mathrm{~K}$ regulatory subunit. Nature 366: 707-710.

Hamaguchi, J.R., R.A. Tobey, J. Pines, H.A. Crissman, T. Hunter, and E.M. Bradbury. 1992. Requirement for p34 $4^{\text {cdc2 }}$ kinase is restricted to mitosis in the mammalian cdc2 mutant Ft210. J. Cell Biol. 117: 1041-1053.

Harper, J.W., G.R. Adami, N. Wei, K. Keyomarsi, and S.J. Elledge. 1993. The p2l cdk-interacting protein cipl is a potent inhibitor of G1 cyclin-dependent kinases. Cell 75: 805816.

Hayles, J., D. Fisher, A. Woollard, and P. Nurse. 1994. Temporal order of $\mathrm{S}$ phase and mitosis in fission yeast is determined by the state of the p34cdc2-mitotic cyclin complex. Cell 78: 813-822.

Hinds, P.W., S. Mittnacht, V. Dulic, A. Amold, S.I. Reed, and R.A. Weinberg. 1992. Regulation of retinoblastoma protein functions by ectopic expression of human cyclins. Cell 70: 993-1006.

Holloway, S.L., M. Glotzer, R.W. King, and A.W. Murray. 1993. Anaphase is initiated by proteolysis rather than by the inactivation of maturation promoting factor. Cell 73: 13931402.

Kelly, T.J., G.S. Martin, S.L. Forsburg, R.J. Stephen, A. Russo, and P. Nurse. 1993. The fission yeast cdcl8 + gene product couples $S$ phase to start and mitosis. Cell 74: 371-382.

Knoblich, J.A. and C.F. Lehner. 1993. Synergistic action of Drosophila cyclin A and cyclin B during the G2-M transition. EMBO I. 12: 65-74.

Knoblich, J.A., K. Sauer, L. Jones, H. Richardson, R. Saint, and C.F. Lehner. 1994. Cyclin E controls S phase progression and its downregulation during Drosophila embryogenesis is required for the arrest of cell proliferation. Cell 77: 107-120.

Kreutzer, M.A., J.P. Richards, M.N. DeSilva-Udawatta, J.J. Temenak, J.A. Knoblich, C.F. Lehner, and K.L. Bennett. 1995 Caenorhabditis elegans cyclin A- and B-type genes: A cyclin A multigene family, an ancestral cyclin B3 and differential germline expression. I. Cell Sci. (in press).

Lees, E., B. Faha, V. Dulic, S.I. Reed, and E. Harlow. 1992. Cyclin $\mathrm{E} / \mathrm{cdk} 2$ and cyclin $\mathrm{A} / \mathrm{cdk} 2$ kinases associate with p107 and E2F in a temporally distinct manner. Genes \& Dev. 6: 1874 1885.

Lehner, C.F. and P.H. O'Farrell. 1989. Expression and function of Drosophila cyclin A during embryonic cell cycle progression. Cell 56: 957-968.

- 1990a. The roles of Drosophila cyclin A and cyclin B in mitotic control. Cell 61: 535-547.

- 1990b. Drosophila cdc2 homologs-A functional homolog is coexpressed with a cognate variant. $E M B O \quad I$ 9: 3573-3581.

Lehner, C.F., N. Yakubovich, and P.H. O'Farrell. 1991. Exploring the role of Drosophila cyclin $\mathrm{A}$ in the regulation of $\mathrm{S}$ phase. Cold Spring Harbor Symp. Quant. Biol. 56: 465-475.

Li, Y., C. Graham, S. Lacy, A.M.V. Duncan, and P. Whyte. 1993. The adenovinus $\mathrm{Ela}$-associated $130-\mathrm{kD}$ protein is encoded by a member of the retinoblastoma gene family and physically interacts with cyclin A and cyclin E. Genes \& Dev. 7: 23662377.

Maldonado-Codina, G., S. Llamazares, and D.M. Glover. 1993. Heat shock results in cell cycle delay and synchronisation of mitotic domains in cellularised Drosophila melanogaster embryos. I. Cell Sci. 105: 711-720.

Peter, M. and I. Herskowitz. 1994. Direct inhibition of the yeast cyclin-dependent kinase cdc28-cln by farl. Science 265: 1228-1231.

Polyak, K., M.-H. Lee, H. Erdjument-Bromage, A. Koff, J.M. Rob- 
erts, P. Tempst, and J. Massague. 1994. Cloning of p27Kipl, a cyclin-dependent kinase inhibitor and a potential mediator of extracellular antimitogenic signals. Cell 78: 59-66.

Quelle, D.E., R.A. Ashmun, S.A. Shurtleff, J.Y. Kato, D. Barsagi, M.F. Roussel, and C.J. Sherr. 1993. Overexpression of mouse D-type cyclins accelerates Gl phase in rodent fibroblasts. Genes \& Dev. 7: 1559-1571.

Richardson, H.E., L.V. O'Keefe, S.I. Reed, and R. Saint. 1993. A Drosophila G1-specific cyclin E homolog exhibits different modes of expression during embryogenesis. Development 119: 673-690.

Saka, Y. and M. Yanagida. 1993. Fission yeast cut5+, required for $S$ phase onset and $M$ phase restraint, is identical to the radiation damage repair gene rad4 + . Cell 74: 383-393.

Schneider, K.R., R.L. Smith, and E.K. O'Shea. 1994. Phosphateregulated inactivation of the kinase pho80-pho85 by the cdk inhibitor pho81. Science 266: 122-126.

Serrano, M., G.J. Hannon, and D. Beach. 1993. A new regulatory motif in cell-cycle control causing specific inhibition of cyclin D/cdk4. Nature 366: 704-707.

Sherr, C.J. 1993. Mammalian Gl cyclins. Cell 73: 1059-1065.

Slingerland, J.M., L. Hengst, C.H. Pan, D. Alexander, M.F. Stampfer, and S.I. Reed. 1994. A novel inhibitor of cyclin-cdk activity detected in transforming growth factor $\beta$-arrested epithelial cells. Mol. Cell. Biol. 14: 3683-3694.

Smith, A.V. and T.L. Orr-Weaver. 1991. The regulation of the cell cycle during Drosophila embryogenesis-The transition to polyteny. Development 112: 997-1008.

Solomon, M.J. 1993. Activation of the various cyclin/cdc2 protein kinase. Curr. Opin. Cell Biol. 5: 180-186.

Stern, B., G. Ried, N.J. Clegg, T.A. Grigliatti, and C.F. Lehner. 1993. Genetic analysis of the Drosophila cdc2 homolog. Development 117: 219-232.

Surana, U., A. Amon, C. Dowzer, J. McGrew, B. Byers, and K. Nasmyth. 1993. Destruction of the CDC28/CLB mitotic kinase is not required for the metaphase to anaphase transition in budding yeast. EMBO I. 12: 1969-1978.

Toyoshima, H. and T. Hunter. 1994. P27, a novel inhibitor of G1 cyclin-cdk protein kinase activity, is related to p21. Cell 78: $67-74$.

van den Heuvel, S. and E. Harlow. 1993. Distinct roles for cyclin-dependent kinases in cell cycle control. Science 262: 2050-2054.

Weinert, T.A. and L.H. Hartwell. 1988. The RAD9 gene controls the cell cycle response to DNA damage in Saccharomyces cerevisiae. Science 241: 317-322.

Weinert, T.A., G.L. Kiser, and L.H. Hartwell. 1994. Mitotic checkpoint genes in budding yeast and the dependence of mitosis on DNA replication and repair. Genes \& Dev. 8: $652-665$.

Xiong, Y., G.J. Hannon, H. Zhang, D. Casso, R. Kobayashi, and D. Beach. 1993. P21 is a universal inhibitor of cyclin kinases. Nature 366: 701-704. 


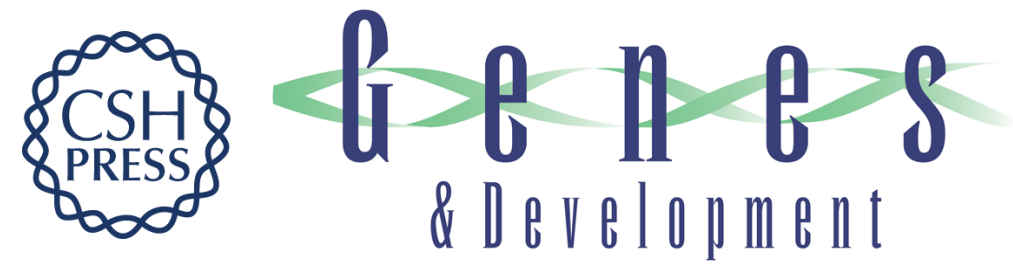

\section{Distinct modes of cyclin E/cdc2c kinase regulation and S-phase control in mitotic and endoreduplication cycles of Drosophila embryogenesis.}

K Sauer, J A Knoblich, H Richardson, et al.

Genes Dev. 1995, 9:

Access the most recent version at doi:10.1101/gad.9.11.1327

References This article cites 55 articles, 22 of which can be accessed free at:

http://genesdev.cshlp.org/content/9/11/1327.full.html\#ref-list-1

License

Email Alerting Service

Receive free email alerts when new articles cite this article - sign up in the box at the top right corner of the article or click here.

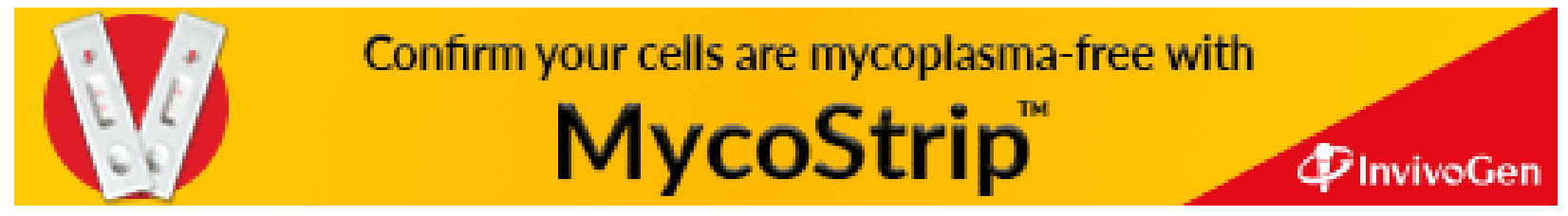

